\title{
Experimental Investigation on Drag Reduction of Vessel Model by Microbubbles
}

\author{
W. Luo, J. M. Wang*
}

Key Laboratory of High Speed Ship Engineering (Wuhan University of Technology), Ministry of Education, Wuhan 430063, China

Email: lwss2005@163.com

\section{Abstract}

The drag reduction is experimentally investigated by means of injecting micro bubble in a large towing basin for a vessel model, which is a $1700 \mathrm{~mm}$ long flat bottom mid-body. There are two battens at the side of the bottom for preventing micro bubbles from transgressing at buoyancy. Micro bubbles are injected from two perforated platesfixed respectively at the bow and in the middle of the bottom of the model. Two air injection equipments are located at the bow and mid of the model respectively. Refer to Figure 1.

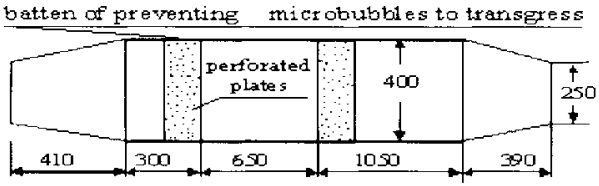

(a) Ship model scale

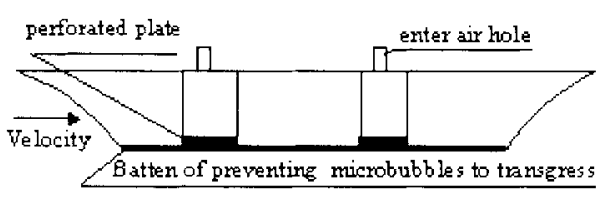

(b) Jet equipment

Figure 1: Model size and perforated silicon plate fixing position

The test is carried out at three waterline of vessel model, five speeds of tow truck, and five gas flow rates with three injection forms. Comparing with no bubbles, the results show that the efficiency of drag reduction by micro bubble injection low waterline is better than deep waterline when the Froude number $\mathrm{Fr} \leq 0.646$ under the condition of same gas flow rates both at the bow and the mid at same time and only at the bow. The angle of trim is smaller at low waterline than deep when $\mathrm{Fr}<0.646$, and there are more increase of the trim angle when $\mathrm{Fr}>0.646$.

The results show that the efficiency of drag reduction by micro bubbles injection both at the bow and the mid of the vessel at same time is better than simply at the bow. The ratio of the total drag reduction about $32.8 \%$ is obtained. The effect on the ratio of the total drag reduction due to the trim of the vessel can be neglected at same speeds and different injection forms.

\section{REFERENCES}

1. Madavan N.K., Deutsch S., Merkle C.L. Reduction of turbulent skin friction by microbubbles. Phys. Fluids, 1984;27(2):356-363

2. Madavan N.K., Deutsch S., Merkle C.L. Measurements of local skin friction in a microbubblemodified turbulent boundary layer. Fluid Mech., 1985;15(6):237-256

3. Dong Wc, Guo RX, Liu XW. Experimental investigation on the resistance reduction of stepped planning craft by formation of air cavity. Journal of Hydrodynamics, 2002;7(4):440-447 